\title{
PERCEPÇÕES SOBRE A COLETA SELETIVA SOLIDÁRIA NA UTFPR CÂMPUS LONDRINA
}

\author{
Amanda Beluque ${ }^{1}$ \\ Tatiane Cristina Dal Bosco² \\ Kátia Valéria Marques Cardoso Prates $^{3}$ \\ Mayra Curti Bonfante ${ }^{4}$ \\ Camila Harumi Sudo ${ }^{5}$
}

Resumo: Instituições públicas federais devem implantar a Coleta Seletiva Solidária, conforme o Decreto n. 5940/2006. Objetivou-se levantar o nível de entendimento da comunidade acadêmica da Universidade Tecnológica Federal do Paraná (UTFPR), câmpus Londrina, acerca da Coleta Seletiva Solidária e sua avaliação quanto ao processo de implantação. Foram aplicados 422 questionários a alunos, professores e técnicos administrativos, totalizando $43 \%$ da população total. Percebeu-se a necessidade de intensificação de ações de sensibilização ambiental de modo a promover, gradativamente, o difícil processo de mudança de comportamento, tão necessário para a completa adesão e funcionamento de um programa de Coleta Seletiva Solidária institucional.

Palavras-chave: Decreto $n^{\circ}$. 5940/2006, Educação ambiental, Instituição de ensino, Resíduos sólidos.

\footnotetext{
${ }^{1}$ Universidade Tecnológica Federal do Paraná. E-mail: amanda.beluque@gmail.com

${ }^{2}$ Universidade Tecnológica Federal do Paraná. E-mail: tatianebosco@utfpr.edu.br

${ }^{3}$ Universidade Tecnológica Federal do Paraná. E-mail: kprates@utfpr.edu.br

${ }^{4}$ Universidade Tecnológica Federal do Paraná. E-mail: mayra_pih@hotmail.com

${ }^{5}$ Universidade Tecnológica Federal do Paraná. E-mail: camilasudo@utfpr.edu.br
} 


\section{Introdução}

A Política Nacional de Resíduos Sólidos (PNRS), sancionada pela Lei $\mathrm{n}^{\circ}$. 12.305/2010 (BRASIL, 2010), atribui a responsabilidade do gerenciamento dos resíduos sólidos aos municípios e aos geradores, sendo marcante a importância da implantação da coleta seletiva e de incentivos à reciclagem. A coleta seletiva é um instrumento da PNRS e é definida por esta lei como "coleta de resíduos sólidos previamente segregados conforme sua constituição ou composição".

Dentro desse contexto, o Decreto Federal $n^{\circ} .5940$ de 25 de outubro de 2006 (BRASIL, 2006) determina a separação dos resíduos recicláveis descartados pelos órgãos e entidades da administração pública federal direta e indireta, na fonte geradora, e a sua destinação às associações e cooperativas dos catadores de materiais recicláveis. Esse processo denomina-se Coleta Seletiva Solidária.

Na Agenda Ambiental da Administração Pública (A3P) (BRASIL, 2009), a Coleta Seletiva Solidária também é entendida como uma estratégia que busca a construção de uma cultura institucional para um novo modelo de gestão dos resíduos, somada aos princípios e ações da A3P.

Em cumprimento à referida Lei e Decreto, a Universidade Tecnológica Federal do Paraná (UTFPR), Câmpus Londrina, iniciou em 2012 o processo de implantação da Coleta Seletiva Solidária, também por entender sua função de formação de indivíduos sensibilizados e responsáveis do ponto de vista ambiental. Para tanto, uma comissão composta por professores, técnicos administrativos e alunos foi instituída, denominada de Comissão de Gestão de Resíduos Sólidos.

Outras universidades relatam suas experiências na implantação da Coleta Seletiva Solidária. A Universidade de Brasília, por exemplo, implantou o processo oficialmente em 2007, como forma de atender o Decreto Federal $n^{\circ}$. 5940/2006 (UnB, 2011, p. 7). Já a Universidade Federal do Rio Grande do Sul iniciou o processo a partir da estruturação de um Sistema de Gestão Ambiental lançado em 2005 (CAMPANI et al., 2008, p.2).

Observa-se que esses processos de implantação da Coleta Seletiva Solidária passaram por uma primeira fase de diagnóstico da realidade. Borges et al. (2013), visando analisar o perfil ambiental dos Institutos Federais brasileiros, realizaram pesquisa empregando um questionário enviado via $e$ mail e correio postal para os diretores-gerais de todos os câmpus existentes no Brasil na época. Essa metodologia mostrou-se ser de grande valia para diagnosticar as práticas e desempenho ambiental nestas e em outras instituições de ensino, pesquisa e extensão públicas. Corrêa et al. (2012), no Centro de Engenharias da Universidade Federal de Pelotas, aplicaram questionários para levantar $o$ nível de conhecimento e interesse da comunidade bem como inseri-la no processo de planejamento da coleta seletiva. A partir dos resultados, foram realizadas ações de sensibilização como cursos, palestras e debates.

revista brasileira educação ambiental 
Aquino (2008) evidencia as dificuldades encontradas na implantação da coleta seletiva na Universidade Federal de Viçosa, causadas principalmente pela falta do senso de corresponsabilidade individual pela geração de resíduos. O autor destaca a importância da Educação Ambiental no sentido de se obter a sensibilização e participação comunitária integrada, fatores indispensáveis para obtenção de êxito em um programa de coleta seletiva.

Dentro desse contexto, o objetivo deste trabalho foi levantar o nível de entendimento da comunidade acadêmica da UTFPR Câmpus Londrina acerca da Coleta Seletiva Solidária, sua avaliação quanto à implantação e, assim, orientar as ações da comissão a partir do ano de 2014.

\section{Metodologia}

A primeira etapa do trabalho da Comissão de Gestão de Resíduos Sólidos da UTFPR Câmpus Londrina foi a realização de um diagnóstico a fim de identificar a necessidade de adequação da estrutura do Câmpus no que se refere aos acondicionadores da coleta seletiva. Em seguida, houve 0 planejamento para definir a forma como seria realizada a coleta no Câmpus e a compra dos materiais necessários. A terceira etapa foi a da implantação: colocação de lixeiras, adequação do abrigo de resíduos e orientação da comunidade acadêmica. A quarta foi o monitoramento, realizado por meio da análise qualitativa dos resíduos recicláveis gerados no Câmpus. Por último, fez-se a avaliação dos resultados desse processo e visitas aos setores para aplicação de um questionário com o intuito de embasar a tomada de decisão e o plano de ação anual da comissão.

Desse modo, foram desenvolvidos dois questionários para a coleta de dados: um aplicado aos alunos e outro aos professores e técnicos administrativos. Essa diferenciação se deu pelo fato de, no ano anterior, a Comissão de Gestão de Resíduos Sólidos da UTFPR Câmpus Londrina já ter abordado os professores e técnicos administrativos com ações de sensibilização. Desse modo, era desejado saber os efeitos destas ações.

As perguntas direcionadas aos alunos estiveram relacionadas com o conhecimento acerca da implantação da Coleta Seletiva Solidária no Câmpus, o meio com que foram informados sobre esse processo e a opinião a respeito da melhor forma de divulgação das informações. Também visou-se identificar a opinião quanto à eficiência da coleta seletiva, sua importância para o Câmpus e o conhecimento sobre o correto descarte de cada resíduo, buscando identificar quais eram as principais dúvidas. Por fim, perguntou-se para quais públicos as ações de sensibilização deveriam ser intensificadas.

Aos professores e técnicos administrativos, além das perguntas aplicadas aos alunos, questionou-se sobre o uso de copos descartáveis e as principais mudanças observadas desde a implantação da coleta seletiva no Câmpus. 
A aplicação dos questionários foi feita por estagiários e alunos de projeto de extensão relacionados à Comissão de Gestão de Resíduos Sólidos, no período compreendido entre 21 a 25 de outubro de 2013. Foram abordados 383 alunos dos cursos superiores existentes no Câmpus: Engenharia Ambiental, Engenharia de Materiais, Engenharia Mecânica, Tecnologia em Alimentos e Licenciatura em Química, o equivalente a $48 \%$ do total de alunos. A abordagem foi feita nas salas de aula, onde os alunos respondiam individualmente o questionário impresso.

Para os professores, os questionários foram aplicados nas salas de aula, em conjunto com a abordagem dos alunos e na sala dos professores, totalizando 23 entrevistados, ou seja, $12,1 \%$ da população total. Quanto aos técnicos administrativos, aplicou-se o questionário impresso nos próprios setores de trabalho a 16 pessoas, o equivalente a $31 \%$ do total.

Após a coleta de dados, efetuou-se a tabulação com ajuda do software Excel, assim como a elaboração dos gráficos para análise e discussão dos resultados.

\section{Resultados e discussão}

\section{Alunos}

Buscou-se identificar se os alunos sabem que no Câmpus está instituído o programa de Coleta Seletiva Solidária (Figura 1).

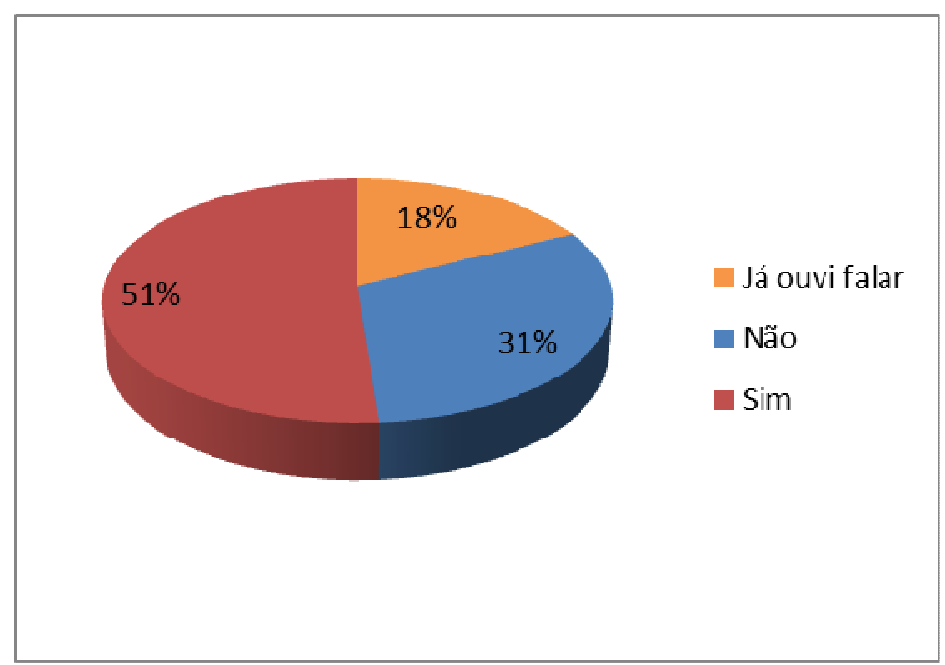

Figura 1: Gráfico referente às respostas dos alunos para a questão: "Você sabia que na UTFPR Londrina está instituído o programa de Coleta Seletiva Solidária?".

Fonte: Autoria própria.

Como se observa na Figura 1,51\% dos alunos sabe da existência do programa de Coleta Seletiva Solidária no Câmpus. Embora seja um índice positivo, esse dado mostra que, apesar dos esforços voltados à sensibilização 
do público, ainda é preciso investir na divulgação. Nota-se, portanto, a necessidade de agir de forma mais pontual de acordo com as necessidades específicas de cada grupo. Corroborando com essas constatações, Philippi Jr e Pelicione (2005) afirmam que não existe Educação Ambiental se ela não se efetivar na prática, na vida, no cotidiano das pessoas e depois nos espaços, a partir das necessidades sentidas. Desse modo, é preciso conhecer a realidade, estabelecer os diagnósticos com a participação da população local, realizar levantamentos, pesquisar problemas existentes, eleger prioridades, tomar decisões e encontrar soluções para esses problemas. Também, segundo os preceitos da Lei 9795/99 (BRASIL, 1999), para que seja garantida a efetividade, faz-se necessário que as ações de Educação Ambiental se constituam em um processo integrado, contínuo e permanente.

Com o objetivo de identificar os mecanismos pelos quais os alunos se informam sobre a coleta seletiva no Câmpus, foi estabelecida a seguinte pergunta: "Como você soube do programa de Coleta Seletiva Solidária do Câmpus? A Figura 2 apresenta o percentual de resposta dos alunos.

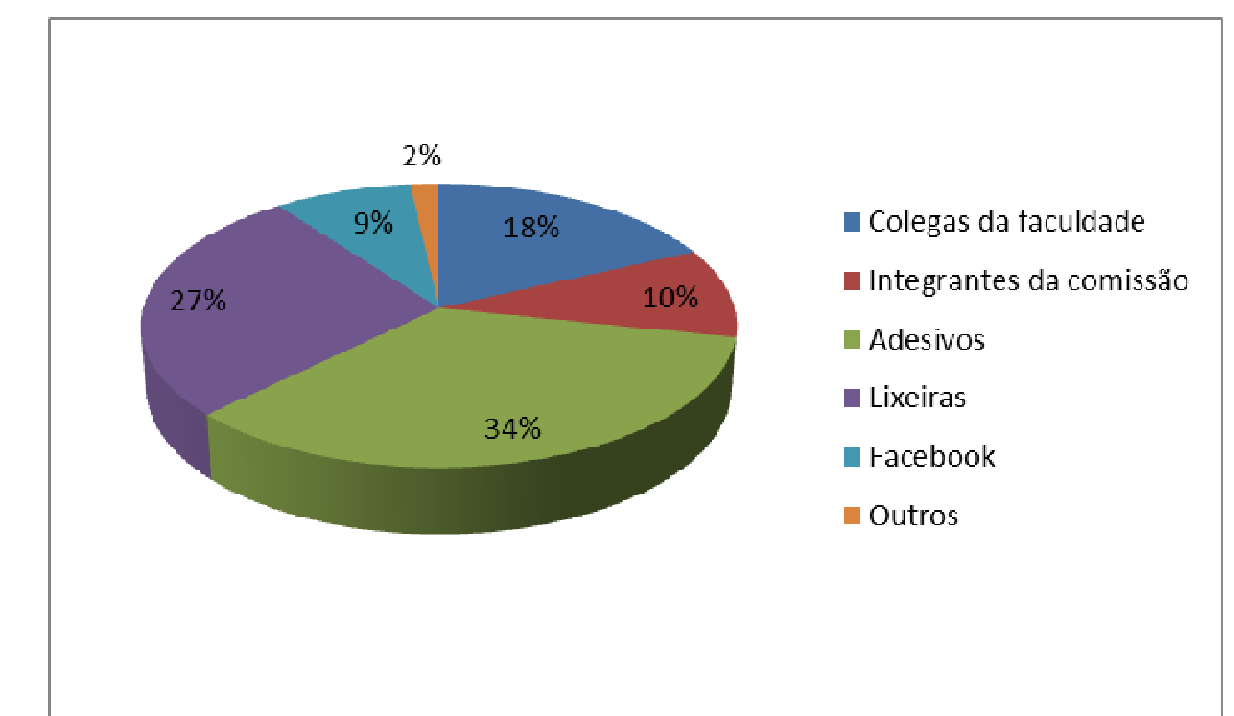

Figura 2: Gráfico referente às respostas dos alunos para a questão: "Como você soube do programa de Coleta Seletiva Solidária do Câmpus?". Fonte: Autoria própria.

Percebe-se, na Figura 2, que a maior parte dos alunos soube do programa de coleta seletiva por meio dos adesivos afixados nas paredes dos sanitários, nas mesas do restaurante universitário (34\%) e das lixeiras alocadas pelo Câmpus (27\%). Com vistas a nortear as ações a serem realizadas pela Comissão em termos de sensibilização, os alunos foram instigados a apontar qual a melhor forma de divulgação das informações sobre coleta seletiva no Câmpus (Figura 3). 


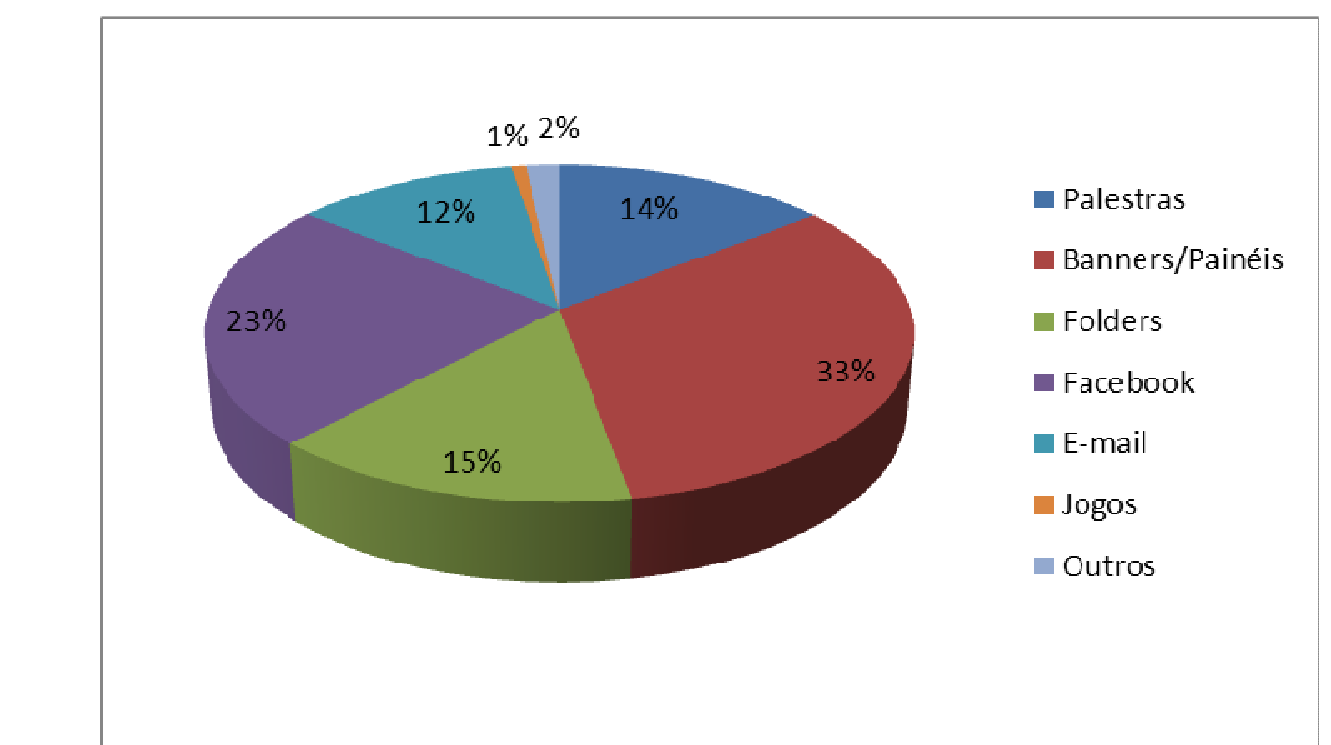

Figura 3: Gráfico referente às respostas dos alunos para a questão: "Na sua opinião, qual a melhor forma de divulgação das informações sobre coleta seletiva no Câmpus?".

Fonte: Autoria própria.

Observa-se, na Figura 3, que se deu preferência à utilização de banners ou painéis (33\%), seguida pela divulgação via Facebook (23\%) e folders (15\%). Segundo Del Rio (1999), a percepção pode ser entendida como um processo mental de interação do indivíduo com o meio ambiente, desenvolvido por mecanismos perceptivos, dirigido pelo estímulo externo, captado pelos cinco sentidos, dos quais a visão é a que mais se destaca. Dessa forma, a sensibilização por meio de estímulos visuais se constitui na melhor alternativa para a divulgação das informações e sensibilização do público-alvo.

Quando questionados sobre a eficiência do programa de coleta seletiva (Figura 4), apenas 35\% dos alunos souberam avaliar e $28 \%$ destes disseram ser eficiente. Segundo Santos (2001), a capacidade de avaliação, dentro do contexto da Educação Ambiental, significa levar os indivíduos ou grupos a avaliar medidas e programas relacionados ao meio ambiente em função de fatores de ordem ecológica, política, econômica, social, estética e educativa. Isso contribui para o aperfeiçoamento do programa e auxilia no direcionamento das ações de sensibilização. Desse modo, percebe-se a importância de colocar os alunos em contato com a realidade da coleta seletiva no Câmpus, permitindo que tirem suas próprias conclusões acerca da eficiência e, dessa forma, possam dar contribuições para a melhoria do processo, bem como promover o comprometimento individual para com o trabalho. 


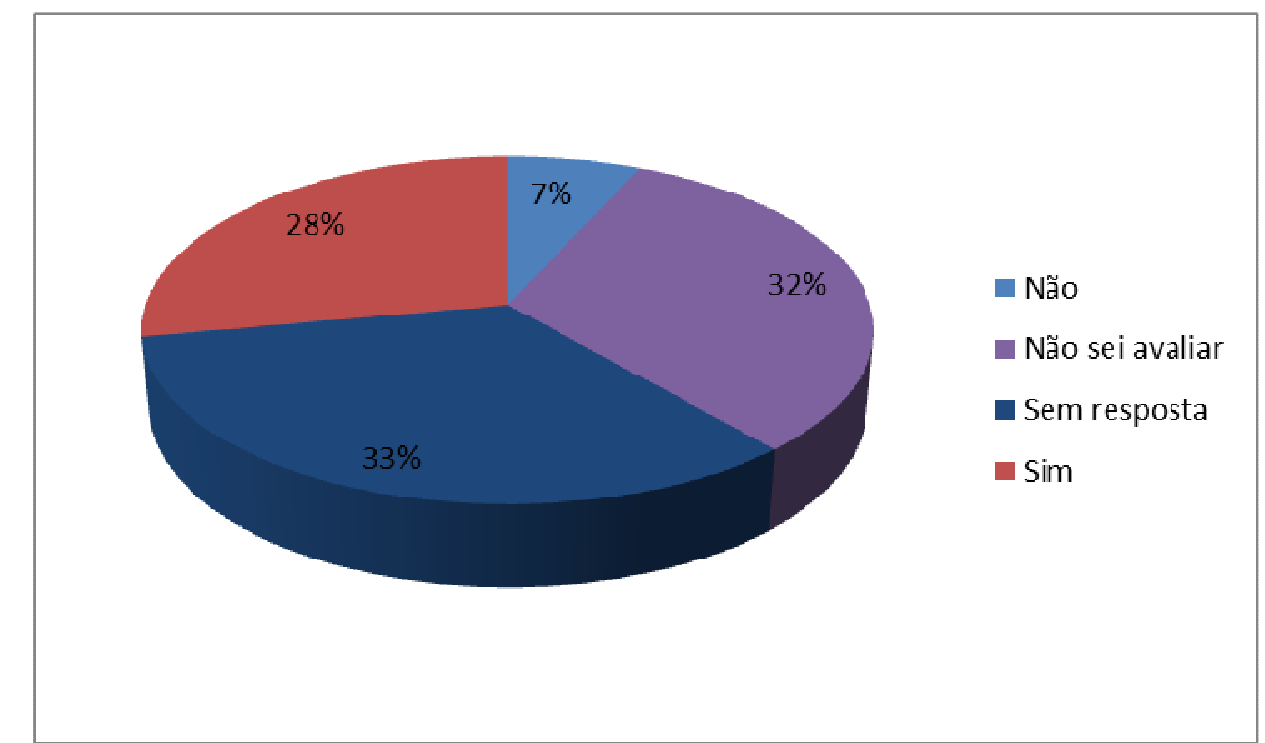

Figura 4: Gráfico referente às respostas dos alunos para a questão: "Você acha que o programa de coleta seletiva está sendo eficiente?".

Fonte: Autoria própria.

Com o intuito de avaliar o desempenho individual dos alunos no processo da coleta seletiva (Figura 5), elaborou-se a seguinte questão: "Você sabe como destinar adequadamente os resíduos no Câmpus?".

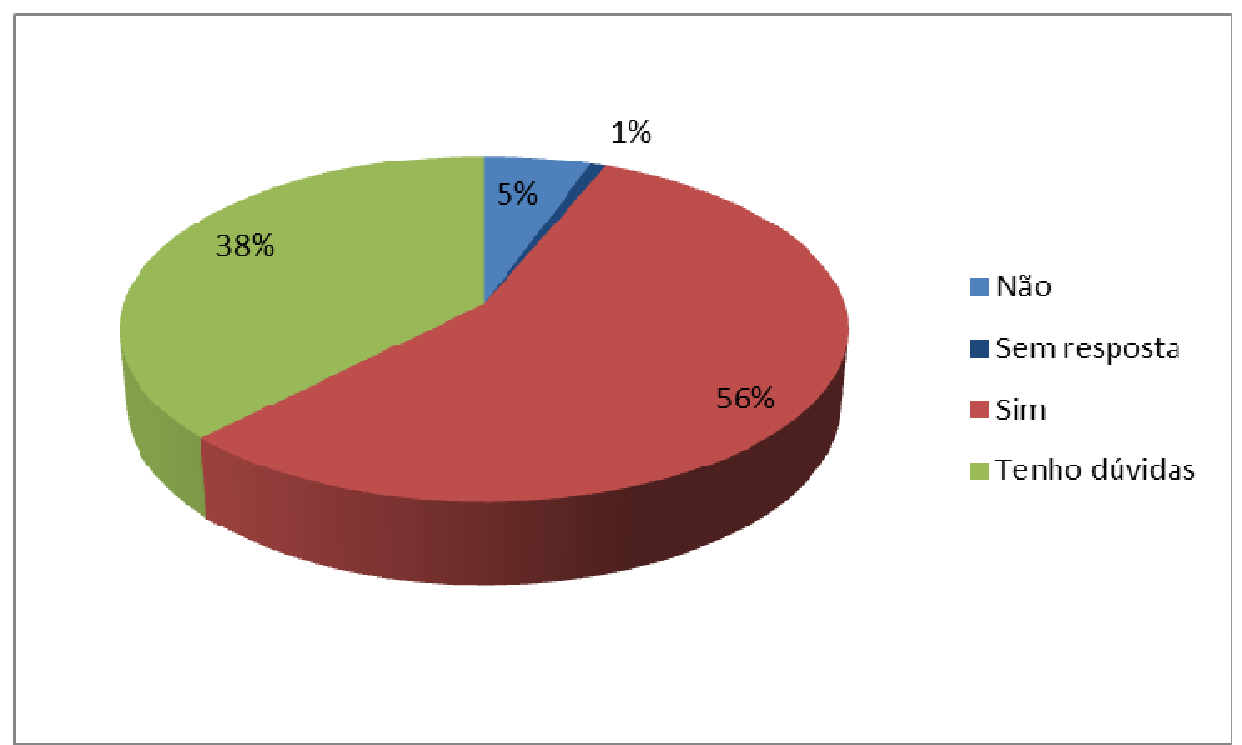

Figura 5: Gráfico referente às respostas dos alunos para a questão "Você sabe como destinar adequadamente os resíduos no Câmpus?".

Fonte: Autoria própria. 
Percebe-se que um número significativo de alunos ainda possui dúvidas $(38 \%)$ ou não sabe (5\%) como destinar adequadamente os resíduos sólidos no Câmpus. Esse resultado demonstra que questões relacionadas à reciclagem e à coleta seletiva devem estar sempre em discussão e, por mais acesso que as pessoas tenham à informação, ainda há dúvidas sobre como proceder. Dessa maneira, a resposta dos alunos para essa questão aponta para a necessidade de um trabalho de formação, com conceitos, contextualização, estudos de caso e relatos de experiências. Sorrentino (1995) afirma que os projetos de Educação Ambiental estão condicionados à promoção da interdisciplinaridade, da visão crítica e holística, da participação e da interação, do autoconhecimento, do resgate de saberes e da resolução de problemas, tendo como conteúdos os problemas ambientais e de qualidade de vida considerados relevantes para os grupos envolvidos.

Com relação às dúvidas apresentadas pelos alunos acerca da Coleta Seletiva Solidária, na Tabela 1, observam-se duas vertentes principais: uma relacionada ao funcionamento do programa e outra relacionada aos procedimentos de descarte e separação dos resíduos sólidos. A Comissão de Gestão de Resíduos Sólidos do Câmpus, ao longo dos dois anos de implantação, vem reunindo esforços para que a sensibilização atinja o públicoalvo de maneira eficiente e as dúvidas sejam sanadas. Esses apontamentos dos alunos nortearão as ações de sensibilização a partir de 2014.

Tabela 1: Principais dúvidas dos alunos quanto à Coleta Seletiva Solidária.

\begin{tabular}{l}
\hline \multicolumn{1}{c}{ ALUNOS } \\
\hline Onde jogar materiais sujos? \\
\hline Dúvida quanto ao descarte/separação dos materiais. \\
\hline Associação de cores das lixeiras com os respectivos resíduos. \\
\hline Quem é a equipe responsável pela Coleta Seletiva Solidária e como estão \\
os índices de eficiência do projeto? \\
\hline Para onde são destinados os resíduos? \\
\hline O que significa "Solidária"? \\
\hline O que é o projeto? Qual a importância social e econômica?
\end{tabular}

Fonte: Autoria própria.

Visando avaliar os conhecimentos dos alunos sobre a coleta seletiva, uma das questões propôs a associação do tipo de resíduo com a lixeira correspondente. A Figura 6 apresenta o percentual de acertos e erros dos alunos nas associações propostas. 


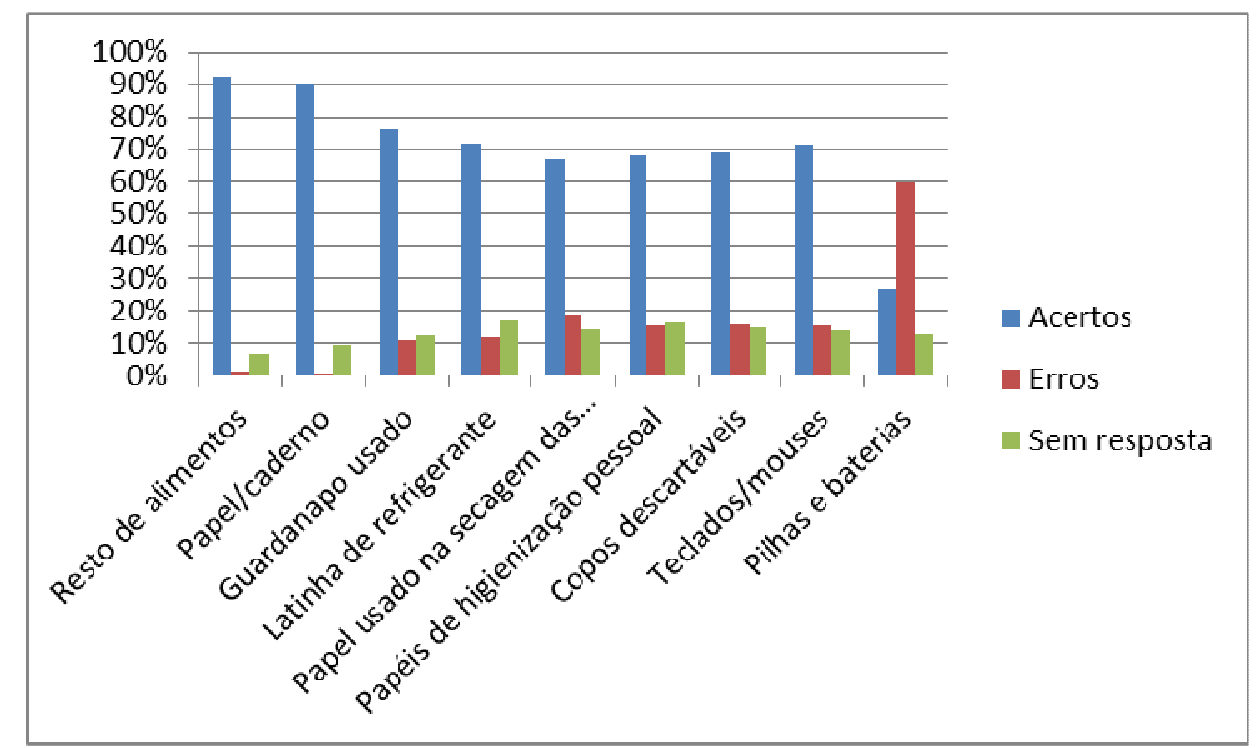

Figura 6: Gráfico referente ao teste de conhecimento aplicado aos alunos.

Fonte: Autoria própria.

Observa-se, na Figura 6, que existe uma contradição com os dados da Tabela 1, na qual se observa uma alta porcentagem de acertos quanto ao descarte dos resíduos. Esse fato pode ter ocorrido devido ao compartilhamento de informações dentro de sala de aula no momento do preenchimento dos questionários, não condizendo, portanto, com a realidade observada.

A implantação da coleta seletiva numa instituição passa pela adequação dos acondicionadores nos locais de geração de resíduos. Dessa forma, considerando que a UTFPR Câmpus Londrina fez um investimento para adequar a estrutura de lixeiras conforme exige a Resolução CONAMA 275/2001 (CONAMA, 2001), perguntou-se aos alunos sua opinião quanto à localização e à distribuição das lixeiras no Câmpus: $75 \%$ dos alunos disseram que a localização e distribuição das lixeiras é adequada, 15\% disseram que não é adequada e os outros $10 \%$ não sabiam avaliar ou não responderam. Questionados, em seguida, se a quantidade de lixeiras é suficiente, $81 \%$ dos alunos responderam positivamente, $16 \%$ acham que é insuficiente e $1 \%$ pensa ser exagerada a quantidade de lixeiras.

Dentro do percentual de alunos que consideraram insuficiente a quantidade de lixeiras no Câmpus (16\%), alguns sugeriram que as de resíduos orgânicos fossem colocadas nas salas de aula, em alguns laboratórios e nos corredores. Percebe-se que a maioria dos alunos considera adequada a localização, distribuição e quantidade de lixeiras na Universidade. Esse dado indica um bom planejamento realizado na implantação da coleta seletiva e aponta para a adequação de situações específicas, que só são percebidas quando se conhece pontualmente a rotina de cada ambiente e de cada trabalho, como no caso dos laboratórios. 
Visando avaliar a percepção dos alunos quanto à observação cotidiana da prática da coleta seletiva, fez-se a seguinte pergunta: "Alguma vez você já observou alguém fazendo a separação/descarte inadequado dos resíduos? Relate o que foi observado". Dos alunos entrevistados, $56 \%$ já observaram pessoas descartando resíduos inadequadamente. Foi relatado o descarte incorreto de guardanapos usados no restaurante universitário, a falta de preocupação em descartar os resíduos adequadamente e o descarte inadequado nos banheiros e nas lixeiras em geral. Na sequência, perguntouse: "Em quais grupos devemos intensificar as ações?". Na Figura 7 apresentase o percentual de respostas dos alunos para essa questão. De acordo com os entrevistados, ainda é preciso abordar alunos, professores, técnicos administrativos, terceirizados responsáveis pela limpeza e funcionários do restaurante universitário.

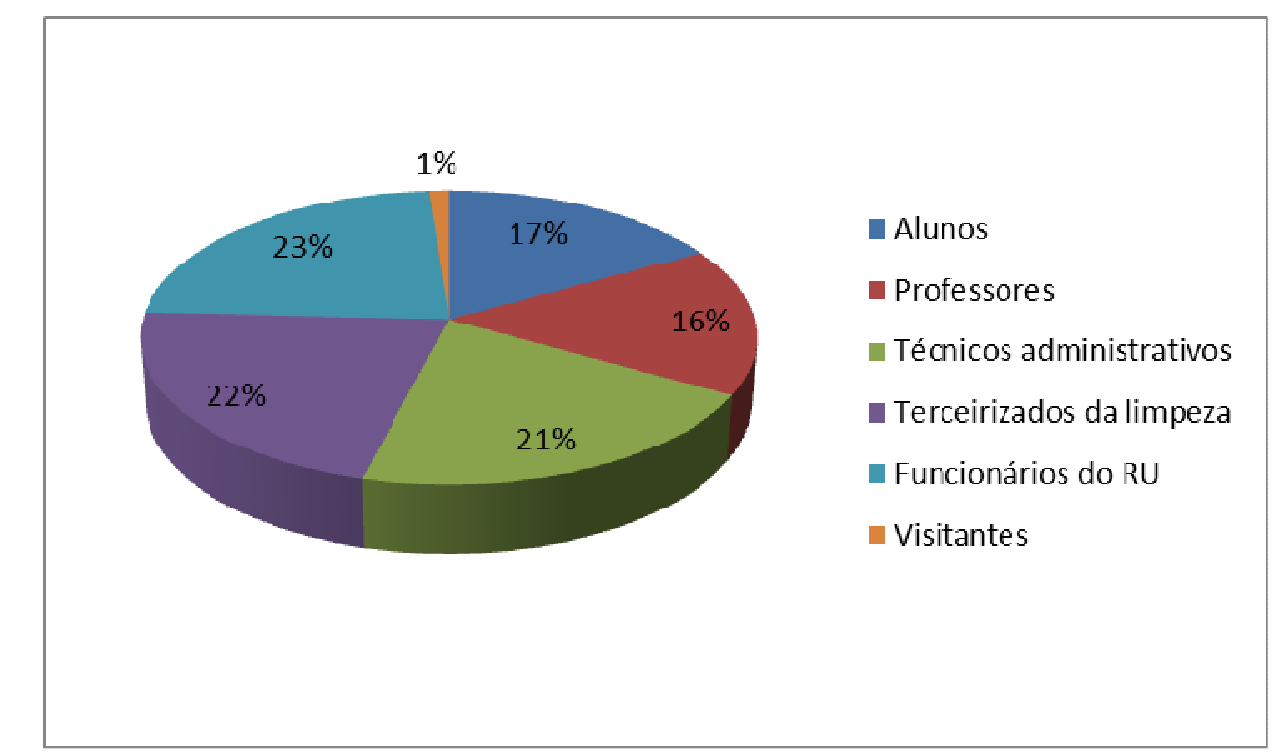

Figura 7: Gráfico referente às respostas dos alunos para a questão: "Em quais grupos devemos intensificar as ações?".

Fonte: Autoria própria.

Os alunos também foram questionados quanto ao nível de importância que atribuem à coleta seletiva realizada no Câmpus (Figura 8). É perceptível o alto grau de importância, existindo de fato envolvimento deles quanto à temática abordada. Esse é um ponto extremamente positivo quanto se trata de garantir a efetividade do programa. Bringhenti e Günther (2011) afirmam que a comunidade deve ser sensibilizada, motivada e os conceitos e práticas precisam ser assimilados e incorporados no cotidiano da população envolvida. Isso contribui para assegurar a operacionalização, continuidade e para atingir os resultados esperados do programa de coleta seletiva. 


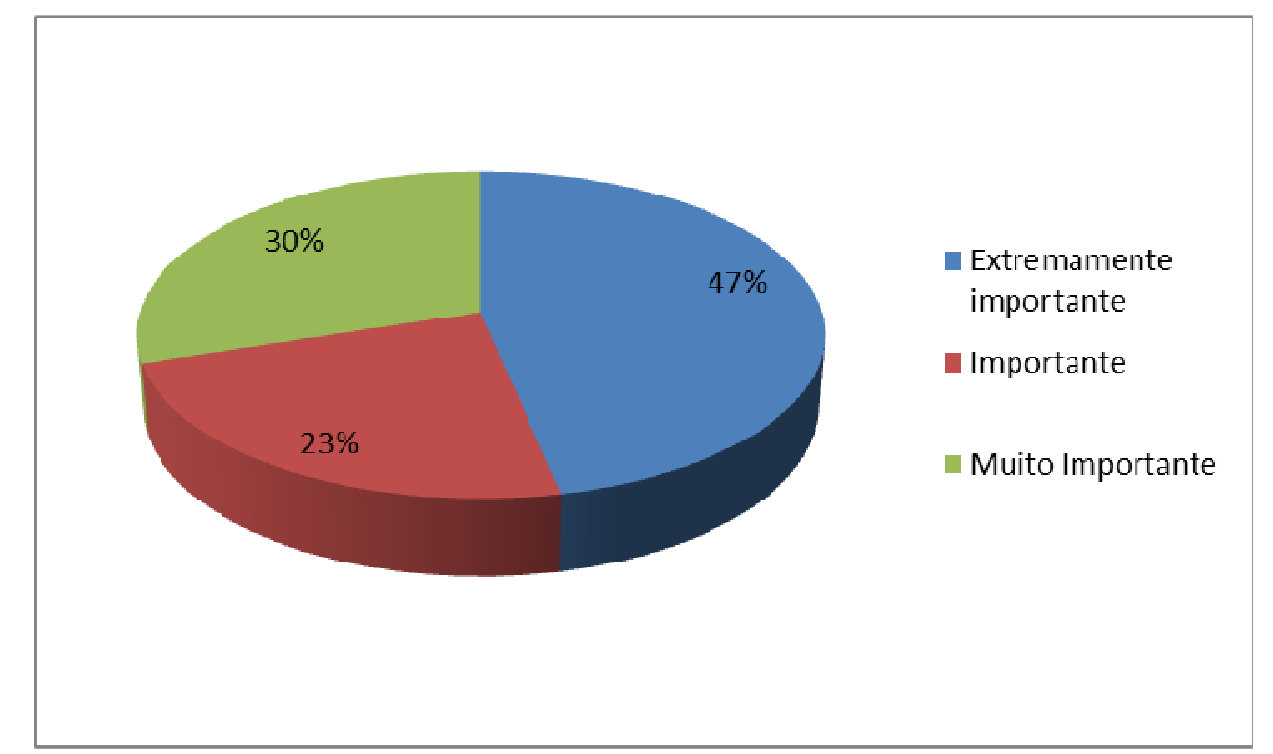

Figura 8: Gráfico referente às respostas dos alunos para a questão: "Qual o nível de importância da coleta seletiva no Câmpus para você?”.

Fonte: Autoria própria.

Devido à constante preocupação com a qualidade do resíduo a ser enviado à cooperativa de catadores, busca-se, por meio das ações desenvolvidas, um resíduo reciclável de alto valor agregado, livre de materiais orgânicos ou rejeitos. Para que isso seja alcançado, é necessário que toda a comunidade acadêmica e pessoas ligadas direta ou indiretamente à Universidade não possuam dúvidas quanto ao descarte dos resíduos no Câmpus.

Primordialmente, as campanhas educativas são voltadas para a não geração dos resíduos e/ou redução na fonte. A redução na fonte é definida pela Agência de Proteção Ambiental dos Estados Unidos da América (2014) como qualquer mudança no projeto, fabricação, compra ou uso de materiais/produtos, inclusive embalagens, de modo a reduzir a sua quantidade ou periculosidade, antes de se tornarem resíduos sólidos. Assim, campanhas como "Traga sua caneca" ou "Dia do copo zero" são postas em prática e vem apresentando resultados positivos.

\section{Professores e técnicos administrativos}

Quando questionados, $57 \%$ dos professores e $73 \%$ dos técnicos administrativos entrevistados afirmaram possuir dúvidas quanto aos procedimentos de descarte dos resíduos sólidos no Câmpus. Esses dados mostram que, apesar dos esforços para a implantação da Coleta Seletiva Solidária, desde 2012, torna-se necessário avaliar as formas de abordagem para com esse público-alvo, apontando para a necessidade de que as ações de sensibilização sejam mais formativas e técnicas. 
As principais dúvidas dos professores e técnicos administrativos com relação à coleta seletiva são apresentadas na Tabela 2.

Tabela 2: Principais dúvidas dos professores e técnicos administrativos quanto à Coleta Seletiva Solidária

\begin{tabular}{|c|c|}
\hline Professores & Técnicos administrativos \\
\hline $\begin{array}{lllll}\begin{array}{l}\text { Onde descartar copos } \\
\text { embalagens sujas? }\end{array} & & & \text { café } & \text { e } \\
\text { embal } & & \end{array}$ & Descarte e separação dos materiais. \\
\hline Para onde é destinado o resíduo? & Frequência de coleta. \\
\hline $\begin{array}{l}\text { Qual a infraestrutura de armazenamento, } \\
\text { logística e reciclagem? }\end{array}$ & Onde jogar pilhas e baterias? \\
\hline $\begin{array}{l}\text { Onde descartar resíduos perigosos de } \\
\text { laboratório? }\end{array}$ & Qual a logística da Coleta. \\
\hline Descarte e associação de cores das lixeiras. & Onde descartar embalagens sujas? \\
\hline $\begin{array}{l}\text { Os professores e técnicos têm sido } \\
\text { cobrados? }\end{array}$ & Associação de cores das lixeiras. \\
\hline
\end{tabular}

Fonte: Autoria própria.

No teste de conhecimentos (Figura 9), observou-se um índice expressivo de perguntas sem resposta nos questionários dos professores. Percebeu-se também que a destinação correta de alguns resíduos precisa ser enfatizada com os técnicos administrativos, como é o caso das pilhas e baterias.

Buscou-se avaliar a percepção dos professores e técnicos administrativos quanto às mudanças no Câmpus desde 2012 quando a coleta seletiva foi implantada. Tanto os professores quanto os técnicos administrativos observaram mudanças relativas (i) à maior quantidade e diversidade de lixeiras; (ii) à maior quantidade de informações divulgadas sobre a coleta seletiva, por meio de murais informativos; (iii) à maior conscientização das pessoas acerca do tema; (iv) a um maior cuidado na hora do descarte; (v) à indisponibilidade de copos descartáveis e uso de caneca/copo próprio. Esses dados indicam que as campanhas e ações de sensibilização estão cumprindo com seu objetivo e mudando alguns hábitos dos servidores.

Em relação aos hábitos diários, questionou-se: "Você faz o uso de caneca/copo próprio? Se não, por quê?". Dos entrevistados, $77 \%$ dos professores e $67 \%$ dos técnicos administrativos afirmaram fazer uso da caneca/copo próprio. Os professores e técnicos administrativos que relataram não usar o seu copo/caneca justificaram que os principais motivos são o esquecimento de trazer o objeto, a difícil higienização e alguns não acham viável, pois "tem que carregar para todos os lados". 

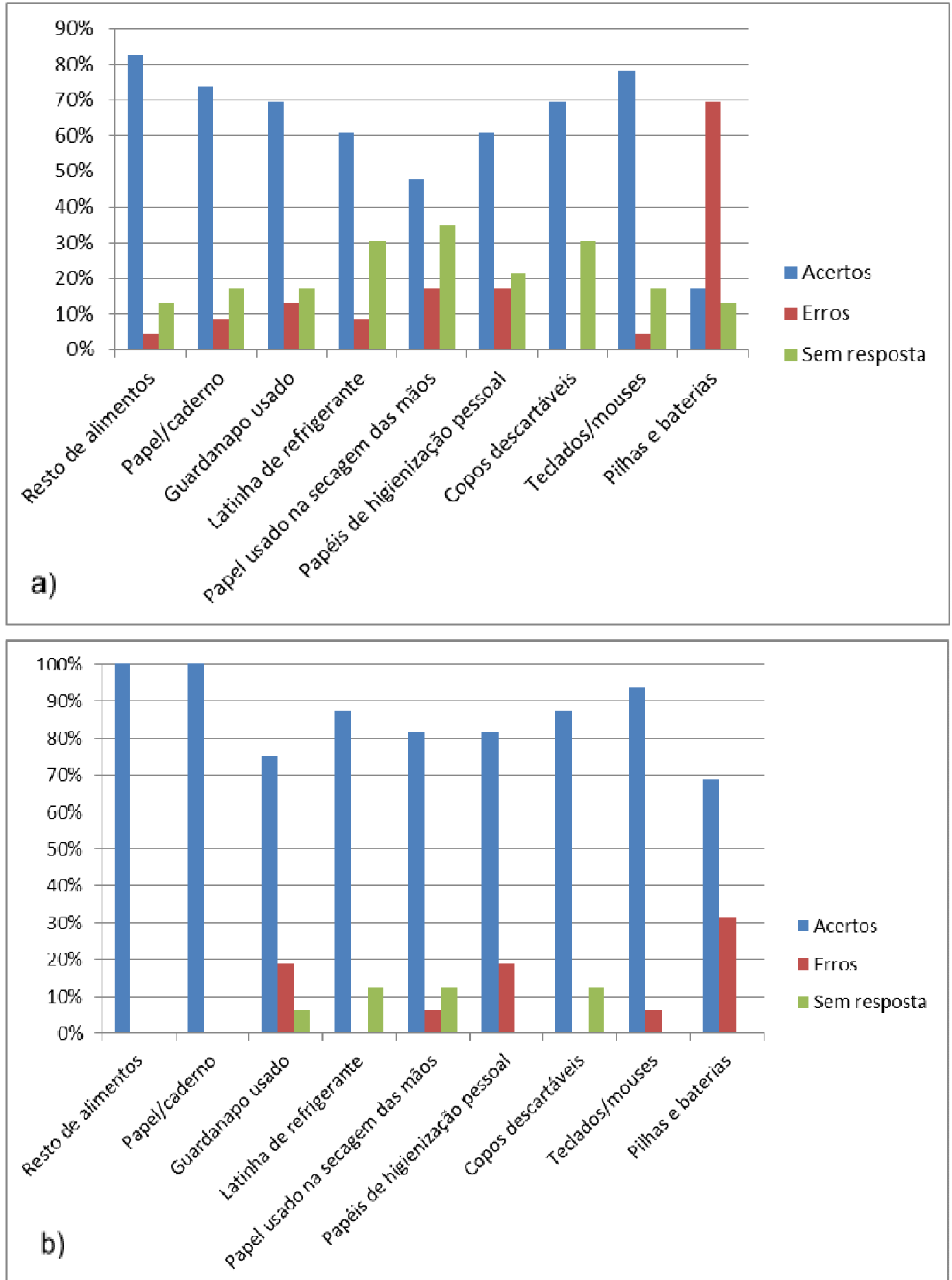

Figura 9: Gráficos referentes ao teste de conhecimentos. a) Respostas dos professores; b) Resposta dos técnicos administrativos. Fonte: Autoria própria. 
Buscou-se identificar a quantidade de copos descartáveis utilizados por dia pelos professores e técnicos administrativos que não aderiram à caneca própria (Figura 10).
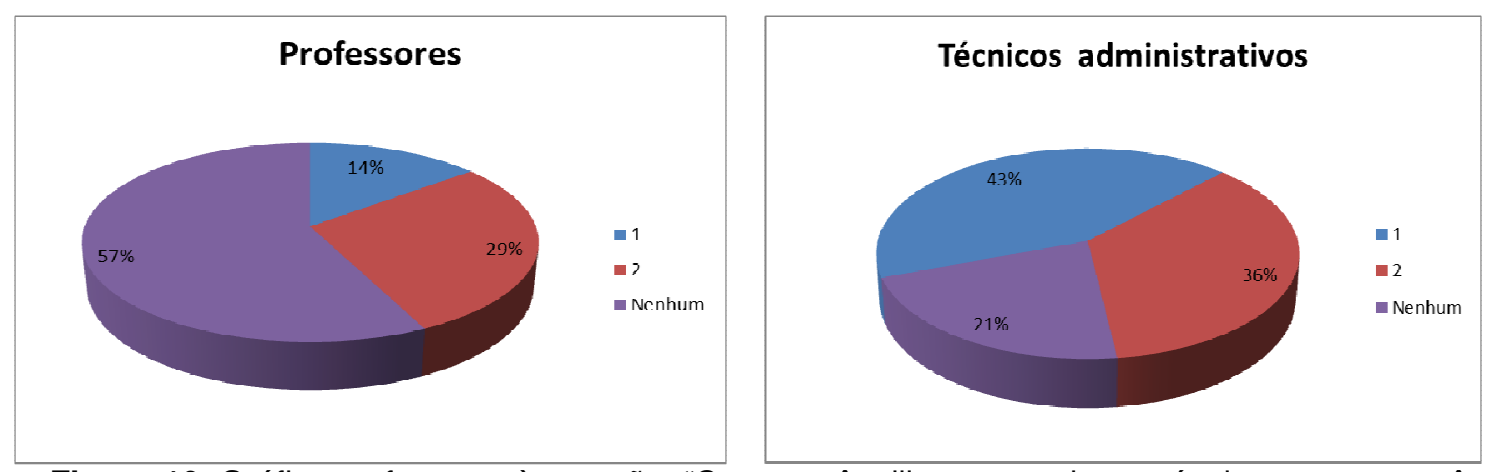

Figura 10: Gráficos referentes à questão: "Caso você utilize copos descartáveis, quantos você descarta por dia?".

Fonte: Autoria própria.

Percebe-se na Figura 10 que a utilização de copos descartáveis é pequena, porém ainda existente apesar das campanhas de sensibilização para o uso da caneca própria. Esses dados refletem a dificuldade da mudança de comportamento dos indivíduos, processo que requer uma ruptura com as estruturas de comportamento pré-existentes e uma reorganização no campo da percepção (GARCIA; SCHMITZ, 2008, p. 1).

Quando questionados sobre a eficiência do programa de coleta seletiva, dos professores entrevistados, $55 \%$ disseram que está sendo eficiente. Os outros $45 \%$ não souberam avaliar. Quanto aos técnicos administrativos, $73 \%$ consideraram o programa eficiente e o restante também não soube avaliar a questão proposta. Esse resultado aponta para a importância da divulgação de dados de monitoramento que indiquem a eficiência da coleta seletiva, de modo que o processo seja mais transparente e que a responsabilidade pela melhoria dos indicadores seja de todos, não apenas da Comissão.

Buscando identificar a melhor forma de abordagem desse público alvo, na Figura 11, pode-se observar que, segundo os professores e técnicos administrativos, a melhor forma de divulgação é por meio de banners e painéis. Assim como observado e discutido no resultado referente aos alunos, percebese que o estímulo visual se sobressai quando comparado às outras formas de divulgação. 

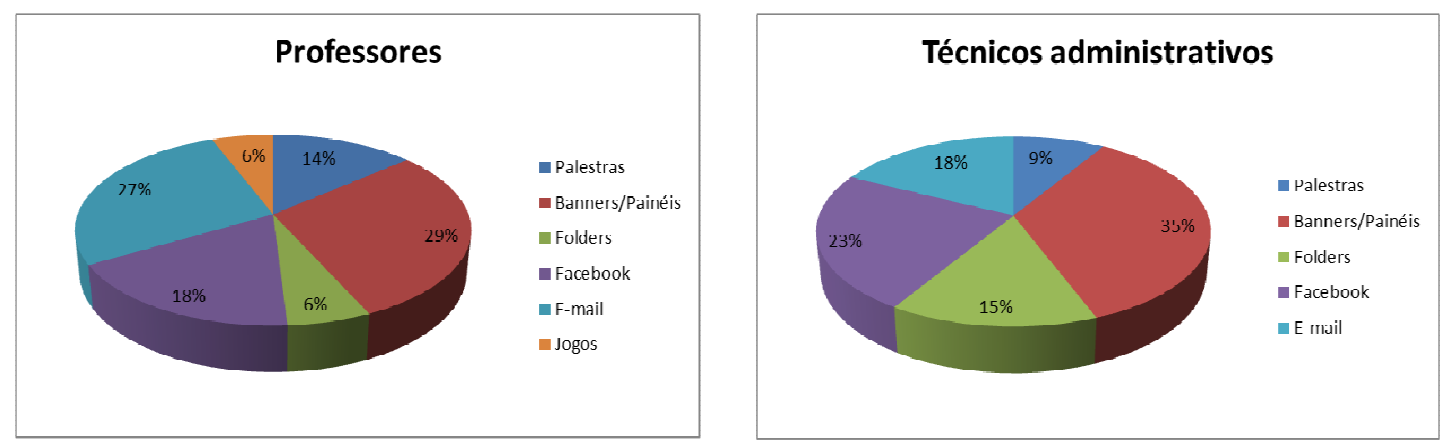

Figura 11: Gráficos referentes à questão: "Na sua opinião, qual a melhor forma de divulgação das informações sobre a coleta seletiva no Câmpus?". Fonte: Autoria própria.

Com relação à percepção dos servidores quanto à localização e à distribuição das lixeiras, $77 \%$ dos professores disseram estar adequadas, $14 \%$ não souberam avaliar e 9\% não acharam adequadas. Entre os técnicos administrativos, 87\% acharam adequadas a localização e distribuição; $13 \%$ não souberam avaliar.

Sobre a quantidade de lixeiras, dos professores entrevistados, $69 \%$ consideraram suficiente, $26 \%$ acharam insuficiente e $5 \%$ consideraram exagerada a quantidade. Dos técnicos administrativos que responderam ao questionário, $87 \%$ consideraram suficiente a quantidade de lixeiras no Câmpus. Os técnicos que consideraram insuficiente (13\%) afirmaram que sentem falta nos laboratórios, corredores e área de uso comum.

Quando questionados se alguma vez já observaram alguém fazendo a separação/descarte inadequado dos resíduos, dos professores entrevistados, $55 \%$ disseram que sim. Entre os técnicos administrativos, a porcentagem dos que já observaram o descarte inadequado foi de $53 \%$. Foi relatado o descarte de resíduo reciclável na lixeira de orgânicos (e vice-versa); mistura dos sacos de lixo pelas terceirizadas da limpeza e descarte incorreto nos banheiros. Essa constatação é um indicativo importante para a Comissão sobre quais problemas precisam ser melhor trabalhados e com quais públicos.

Com vistas a identificar o público alvo das ações de sensibilização prioritárias, observa-se, na Figura 12, que, assim como entre os alunos, não há consenso, ou seja, todos os públicos ainda precisam ser sensibilizados na opinião dos entrevistados.

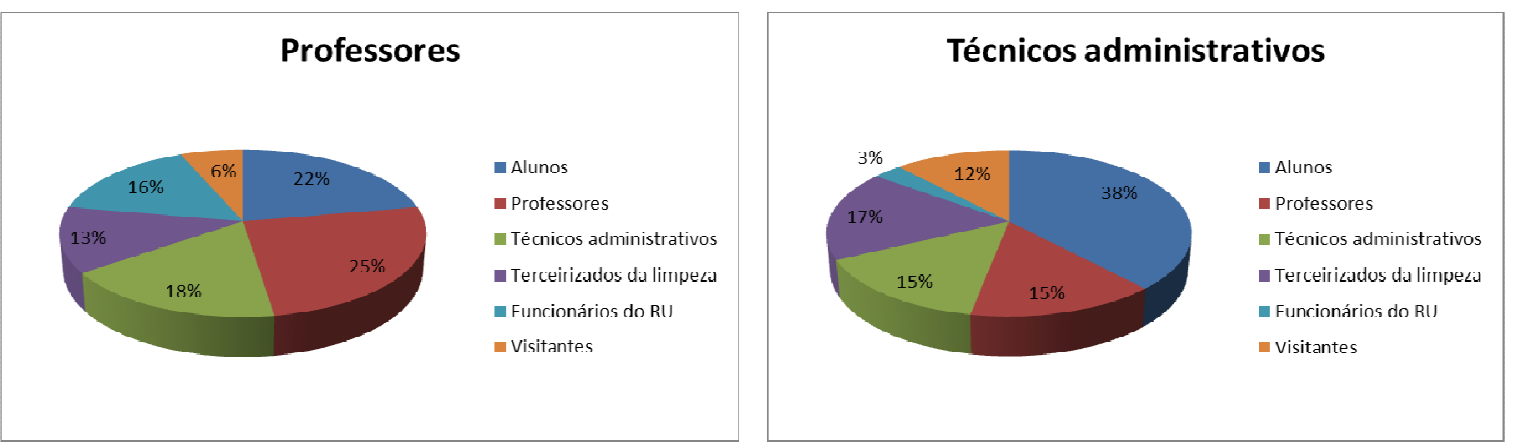

Figura 12: Gráficos referentes à questão: "Ajude-nos a identificar em quais grupos devemos intensificar as ações de sensibilização. Fonte: Autoria própria.

Revbea, São Paulo, V. 10, N 1: 146-163, 2015. 
Por fim, quando questionados sobre o nível de importância da coleta seletiva no Câmpus para os professores e técnicos administrativos, observa-se, na Figura 13, que esse trabalho recebe a devida valorização, motivando, dessa forma, as futuras ações da Comissão de Gestão de Resíduos Sólidos.
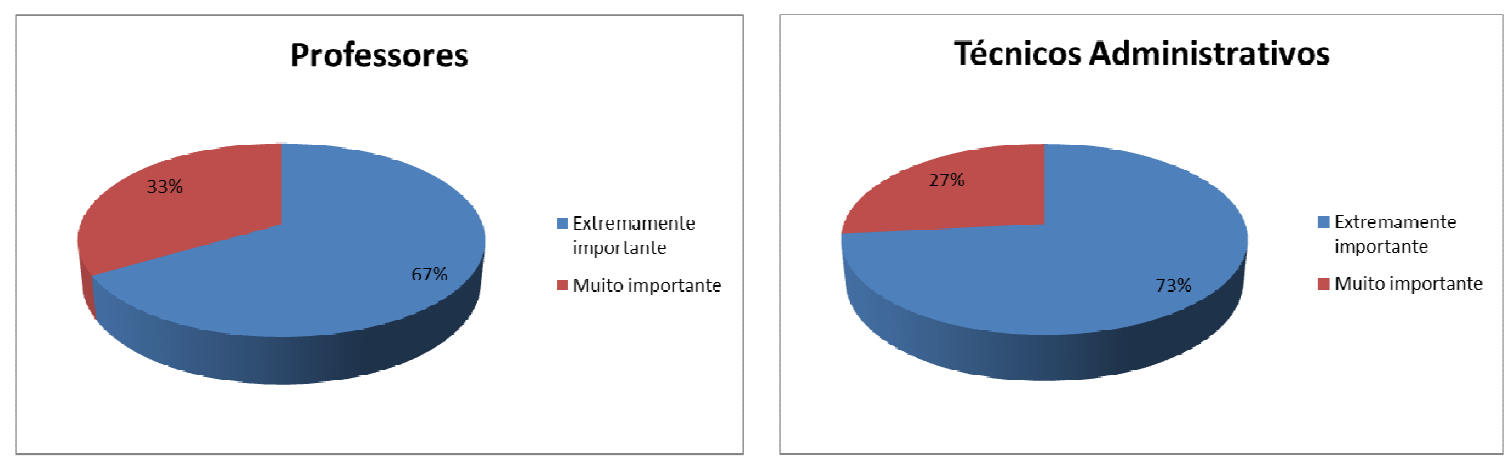

Figura 13: Gráficos referentes à questão: "Qual o nível de importância da coleta seletiva no Câmpus para você?".

Fonte: Autoria própria.

\section{Conclusões}

Os resultados da aplicação dos questionários possibilitaram levantar o nível de entendimento dos alunos e servidores acerca do tema, sua avaliação quanto à implantação do programa na Universidade e orientar as ações da Comissão de Gestão de Resíduos Sólidos a partir de 2014.

Quanto ao nível de entendimento, percebeu-se que, apesar das ações de sensibilização efetuadas pela comissão, tanto os alunos quanto os professores e técnicos administrativos ainda possuem dúvidas sobre 0 descarte de materiais. Essas dúvidas podem levar ao descarte inadequado, prejudicando a qualidade do resíduo gerado. Sendo assim, para que as dúvidas ainda existentes sejam sanadas e haja uma mudança de comportamento das pessoas no sentido de realizar uma correta separação dos resíduos, é fundamental que as ações de sensibilização sejam contínuas, permanentes e voltadas para públicos específicos, abordando aspectos técnicos, de caráter formativo.

À respeito do processo de implantação do programa de Coleta Seletiva Solidária, percebeu-se que a maioria já o conhece e que observaram mudanças visuais e de hábitos decorrentes da implantação desde 2012. Os públicos investigados atribuem grande importância ao desenvolvimento do programa na Universidade, o que motiva a continuação do trabalho.

Percebeu-se que, para os alunos, para os professores e técnicos administrativos, a melhor forma de divulgação é por meio de banners e painéis. Isso mostra que, para cumprir o objetivo de sensibilização, a comissão deve investir em ações que estimulem a percepção visual dos indivíduos.

Os resultados serviram de base para a definição de ações a serem realizadas objetivando atingir alunos, professores, técnicos administrativos, 
servidores terceirizados da limpeza, visitantes e funcionários do Restaurante Universitário. Diversas estratégias serão utilizadas, como: organização de ciclos de palestras técnicas, discussão de filme ambiental, murais, banners, divulgação de informativos no Facebook, visita aos setores e salas de aula para diálogo com a comunidade, entre outras. Somente com a adesão de todos os envolvidos no processo de geração de resíduos um programa de coleta seletiva atingirá sua plenitude e esse é o grande desafio que move o grupo promotor da Coleta Seletiva Solidária na UTFPR Câmpus Londrina.

\section{Agradecimentos}

À Fundação Araucária, pelo apoio financeiro à pesquisa, e à Universidade Tecnológica Federal do Paraná.

\section{Referências}

AQUINO, D. S. Educação ambiental como principal ferramenta da coleta seletiva na Universidade Federal de Viçosa. Revista Ponto de Vista. Viçosa, n. 1, v. 5: 129-140, 2008.

Agência de Proteção Ambiental dos Estados Unidos da América Environmental Protection Agency. Disponível em: http://www.epa.gov/wastes/nonhaz/municipal/index.htm. Acesso em: 25 abr. 2014.

BORGES, A.F.; REZENDE, J.L.P.; BORGES, L.A.C.; BORÉM, R.A.T.; MACEDO, R.L.G.; BORGES, M.A.C.S. Análise da gestão ambiental nos Institutos Federais de Educação Ciência e Tecnologia. Revista Cerne, Lavras, n. 2, v. 19: 177-184, abr./jun. 2013.

BRASIL. Ministério do Meio Ambiente. Agenda ambiental na administração pública (A3P). 5 ed. Brasília, DF. 2009. 100 p. Disponível em: http://www.mma.gov.br/images/arquivo/80063/cartilha\%20completa\%20A3P.pd f. Acesso em: 23 abr. 2014

BRASIL. Ministério do Meio Ambiente. Decreto ${ }^{\circ}{ }^{5}$ 5.940, de 25 de outubro de 2006. Institui a separação dos resíduos recicláveis descartados pelos órgãos e entidades da administração pública federal direta e indireta, na fonte geradora, e a sua destinação às associações e cooperativas dos catadores de materiais recicláveis, e dá outras providências. Disponível em: http://www.planalto.gov.br/ccivil 03/ Ato2004-2006/2006/Decreto/D5940.htm. Acesso em: 23 abr. 2014.

BRASIL. Ministério do Meio Ambiente. Lei ${ }^{\circ}$ 9.795, de 27 de abril de 1999. Dispõe sobre a educação ambiental, institui a Política Nacional de Educação Ambiental e dá outras providências. Disponível em: http://www.planalto.gov.br/ccivil 03/leis//9795.htm. Acesso em: 28 abr. 2014. 
BRASIL. Ministério do Meio Ambiente. Lei $\mathrm{n}^{\circ}$ 12.305, de 02 de agosto de 2010. Institui a Política Nacional de Resíduos Sólidos; altera a Lei no 9.605, de 12 de fevereiro de 1998; e dá outras providências. Disponível em: http://www.planalto.gov.br/ccivil 03/ ato2007-2010/2010/lei/l12305.htm.

Acesso em: 28 abr. 2014.

BRINGHENTI, J.R.; GUNTHER, W.M.R. Participação social em programas de coleta seletiva de resíduos sólidos urbanos. Revista Engenharia Sanitária e Ambiental. Rio de Janeiro, n. 4, v.16: 421-430, out./dez. 2011.

CAMPANI, D.B.; MUNIZ, R.P.D.; TAVARES, M R.P. Implantação da coleta seletiva dos resíduos sólidos do Câmpus do vale e a gestão ambiental da Universidade Federal do Rio Grande do Sul. Revista AIDIS de Ingeniería y Ciencias Ambientales: Investigación, desarrollo y práctica. Cidade do México, n. 4, v.1: 1-10, 2008.

CONAMA Conselho Nacional do Meio Ambiente. Resolução $\mathbf{n}^{\circ}$ 275, de 05 de julho de 2001. Estabelece o código de cores para os diferentes tipos de resíduos, a ser adotado na identificação de coletores e transportadores, bem como nas campanhas informativas para a coleta seletiva. Disponível em: http://www.mma.gov.br/port/conama/legiabre.cfm?codlegi=273. Acesso em: 20 abr. 2014. CORRÊA, É.K.; AVANCINI, A.R.; MONCKS, R.B.; PAZ, M.F.; CORRÊA, L.B. Utilização de ferramentas de educação ambiental na implantação do programa de coleta seletiva no Centro de Engenharias da Universidade Federal de Pelotas. Revista Eletrônica do Mestrado em Educação Ambiental. Rio Grande, n. 1, v.29: 1-16, jul./dez. 2012.

DEL RIO, V. Percepção ambiental: a experiência brasileira. 2. ed. São Paulo, Studio Nobel, 1999.

GARCIA, A.P.S.; SCHMITZ, H. A Educação Ambiental como Intervenção: Aspectos para uma Reflexão. IV Encontro Associação Nacional de PósGraduação e Pesquisa em Ambiente e Sociedade. Jun. 2008. Disponível em: http://www.anppas.org.br/encontro4/cd/ARQUIVOS/GT9-259-284-

20080510195728.pdf. Acesso em: 8 mai. 2014.

PHILIPPI JÚNIOR, A.; PELICIONI, M.C.F. (Ed.). Educação ambiental e sustentabilidade. Barueri, Editora Manole, 2005.

SANTOS, A.F.L. Educação Ambiental: Desenvolvendo o Senso Crítico. 2001. Disponível em: http://www.apoema.com.br/EADesenvolvendo\%200\%20Sens0\%20Critico-Aristides.pdf. Acesso em: 1 mai. 2014.

SORRENTINO, M. Educação Ambiental e universidade: um estudo de caso. 1995. Tese (Doutorado). Faculdade de Educação da USP, São Paulo.

UnB. Universidade de Brasília. Cartilha sobre a Coleta Seletiva Solidária. Disponível em: http://www.unb.br/administracao/decanatos/dex/naa/arquivos/Cartilha\%20Colet a\%20Seletiva\%20Solidaria.pdf. Acesso em: 20 mai. 2014.. 